\title{
Progressive Multifocal Leukoencephalopathy Following Treatment with Rituximab in a Patient with Non- Hodgkin's Lymphoma: Diagnosing a Rare Disease
}

Amanda Woodford*, Gabriella A. Conte, Mary Sedarous and Mohammad A. Hossain

Department of Medicine, Jersey Shore University Medical Center of Hackensack Meridian Health, Neptune, NJ, USA

Correspondence to:

Amanda Woodford

Department of Medicine

Jersey Shore University Medical Center of

Hackensack Meridian Health

Neptune, NJ, USA

E-mail: amawoodford@gmail.com

Received: November 30, 2020

Accepted: January 12, 2021

Published: January 15, 2021

Citation: Woodford A, Conte GA, Sedarous M, Hossain MA. 2020. Progressive Multifocal Leukoencephalopathy Following Treatment with Rituximab in a Patient with Non-Hodgkin's Lymphoma: Diagnosing a Rare Disease. J Neuroimaging Psychiatry Neurol 5(2): 24-28.

Copyright: (C) 2020 Woodford et al. This is an Open Access article distributed under the terms of the Creative Commons Attribution 4.0 International License (CC-BY) (http:// creativecommons.org/licenses/by/4.0/) which permits commercial use, including reproduction, adaptation, and distribution of the article provided the original author and source are credited.

Published by United Scientific Group

\begin{abstract}
Progressive multifocal leukoencephalopathy (PML) is a rare and often fatal neurologic disease that has been known to occur in patients with immunosuppression, due to reactivation of the polyomavirus JC (JC virus). This severe clinical entity is aggressive, involving the white matter and cortex. Clinical manifestations include motor weakness, gait deformities, visual field deficits, speech disturbances, and behavioral abnormalities. Identifying key histopathologic features of PML via brain biopsy remains the gold standard for diagnosis. However, this poses considerable risk to patients and is not without potential sampling errors and complications. The diagnosis of PML can also be accurately made through identifying a triad of (1) clinical features/symptoms; (2) classic neuroimaging findings such as an increased signal on T2-weighted MRI images with fluid-attenuated inversion recover (FLAIR) sequences, and (3) the presence of JC virus on PCR in CSF studies. Reports in the literature exist on the association of PML in patients treated with immunomodulatory drugs, such as Rituximab. As immunosuppressive therapy is being utilized more frequently, it is important for practitioners to be cognizant of the association between immunosuppressive agents, in particular anti-tumor chemotherapeutic agents and biologics and the development of PML. We aim to present an extremely rare and progressive clinicopathologic entity of PML occurring uniquely as a nonenhancing temporal lesion, which differs from the common frontal and parietal lesions, diagnosed on the basis of using clinical symptomatology, radiographic findings and CSF analysis. We suggest that PML should be included in the differential diagnosis and active work-up in patients with recent Rituximab therapy presenting with unexplained clinical and radiographic changes.
\end{abstract}

\section{Keywords}

Progressive multifocal leukoencephalopathy, Rituximab, Non-Hodgkin's lymphoma, JC virus, MRI imaging, Neuroimaging

\section{Introduction}

Progressive multifocal leukoencephalopathy (PML) is a rare and often fatal demyelinating neurologic disease caused by reactivation of the polyomavirus JC ( $\mathrm{JC}$ virus) that occurs mainly in immunosuppressed patients, such as those with HIV-1 infection/acquired immune deficiency syndrome (AIDS), hematologic malignancies, or those undergoing chronic corticosteroid or immunosuppressive therapy for organ transplant [1]. Reports suggest that most primary infections with JC virus occur silently in childhood, however increased seroprevalence is seen with age, as reports state almost $90 \%$ of adults to be seropositive [2]. 
Classically, the diagnosis of PML is made via brain biopsy to examine the histopathology, with features characterized as a triad of demyelination, bizarre astrocytes, and oligodendroglia nuclear inclusions [3]. This method of diagnosis is invasive and not without grave complications. In recent years, diagnostic criteria have been implemented which consider clinical symptoms/presentation, radiograph features and laboratory data collectively to forgo an invasive brain biopsy in making an accurate diagnosis of PML.

The incidence of PML remains low. However, over the past two decades, epidemiologic studies suggest an increased incidence in the number of PML cases related to the use of certain cytotoxic chemotherapeutic and immunosuppressive agents, such as Rituximab [2]. Herein, we present a unique case of a patient with recent exposure to Rituximab for the treatment of Non-Hodgkin's Lymphoma, diffuse large B-cell subtype, who presented with progressively worsening neurologic symptoms and was ultimately diagnosed with PML based on diagnostic symptomatology, distinctive imaging and laboratory findings.

\section{Case Report}

A 58-year old female with a past medical history significant for hairy cell leukemia status-post chemotherapy treatment and subsequent remission, followed by a diagnosis of nonHodgkin's lymphoma (NHL), diffuse large B-cell (DLBCL) subtype, status post systemic chemotherapy with R-CHOP complicated by polyneuropathy, presented as a transfer from an alternate facility for evaluation of progressively worsening neurologic symptoms. The patient was in her usual state of health until her $6^{\text {th }}$ cycle of R-CHOP, about 5 months prior to presentation to our institution, when she developed paresthesias in her hands and feet, which was initially attributed to toxic polyneuropathy prompting discontinuation of vincristine. One month following completion of R-CHOP, she developed progressively worsening lower extremity weakness resulting in falls. She was admitted to a local hospital for possible limbic encephalitis and paraneoplastic syndrome after a negative lumbar puncture yielded a negative bacterial and viral culture and negative cytology. However despite being started on oral prednisone, her functional status continued to deteriorate and she developed significant spasticity in her upper and lower extremities, more pronounced on the left side. She was then transferred to our facility for further management.

Upon presentation, her symptoms progressed to hypotonic speech and new mood instability, described by the patient's family as frequent episodes of crying and mood swings. She denied bladder or bowel incontinence, fevers, chills, confusion, vision changes, or difficulty with swallowing or chewing. She was alert and oriented to person, place, and time. Physical examination was significant for spasticity in the upper and lower extremities, with more weakness in the left upper extremity compared to the right, with long tract signs noted. Her sensory exam included intact proprioception at the toes but decreased sensation to light touch in a stocking distribution. Reflexes were noted to be absent in the upper limbs and achilles, and $2+$ at the patella. Babinski reflex was positive bilaterally. Laboratory studies were significant for a low platelet count of $78 \mathrm{~K} / \mathrm{uL}$ and a low serum immunoglobulin (Ig) concentration of $188 \mathrm{mg} / \mathrm{dL}$ (reference range 768 - $1632 \mathrm{mg} / \mathrm{dL}$ ). MRI of the brain with and without contrast showed significant progression of T2/FLAIR hyperintensity in the subcortical white matter (Figure 1) compared to recent imaging at the prior facility. Given the patient's immunosuppression with recent Rituximab therapy, the differential was expanded to include progressive multifocal leukoencephalopathy (PML) versus primary central nervous lymphoma. Magnetic resonance

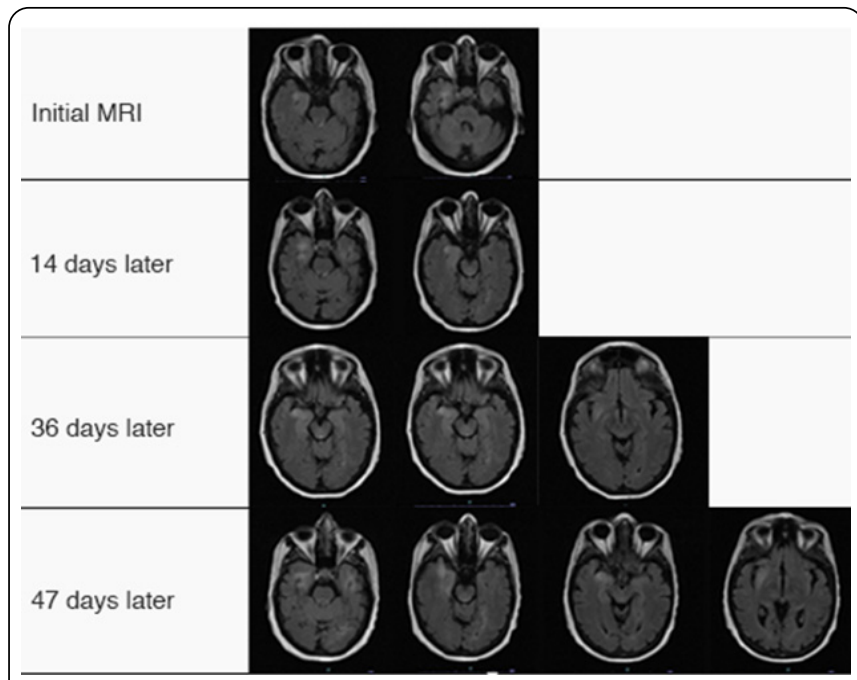

Figure 1: Progression of hyperintensities on brain MRI T2/FLAIR imaging.

Initial MRI showed asymmetric increase T2/FLAIR hyperintensity in the right mesial temporal lobe. Subsequent imaging revealed interval increase in the initial hyperintensity with new involvement of the medial temporal lobe and bilateral perirolandic subcortical white matter, and scattered hyperintensities in the supratentorial periventricular and subcortical white matter. At this point the patient was diagnosed with limbic encephalitis. There was no abnormal enhancement seen to suggest CNS lymphoma. Due to worsening symptoms additional MRIs were obtained which showed increase in T2/FLAIR hyperintensity/cortical thickening of the right mesial temporal lobe, right hippocampus, left medial temporal lobe, and bilateral perirolandic cortical white matter.

spectroscopy was performed, which revealed a region of signal abnormality in the anterior right temporal lobe indicating elevated choline to creatine ratio and decreased NAA peak. EEG demonstrated poorly organized background activity with predominantly delta activity noted, asymmetric slowing on the right compared to the left involving almost all fields, and no evidence of electrographic seizures or definitive epileptiform activity. Lumbar puncture was repeated and showed protein value $69 \mathrm{mg} / \mathrm{dL}$, white blood cell count $4 \mathrm{uL}$, blood glucose $47 \mathrm{mg} / \mathrm{dL}$ and negative HSV (Table 1). Unfortunately, flow cytometry was unable to be obtained due to an insufficient specimen. Cerebral spinal fluid (CSF) studies yielded positive JC virus on PCR. Considering the patient's clinical symptoms, radiographic findings and the demonstration of JC virus via CSF PCR, a diagnosis of probable PML was made. Brain biopsy was considered, however the patient's hospital course was complicated by a spontaneous intraparenchymal hemorrhage. The decision was ultimately made by the family and care team to place the patient on inpatient hospice. 


\begin{tabular}{|c|c|c|c|}
\hline CSF Study & $\begin{array}{l}\text { Reference } \\
\text { Range }\end{array}$ & $\begin{array}{l}\text { Results on } \\
\text { Current } \\
\text { Admission } \\
\left(2^{\text {nd }} L P\right)\end{array}$ & $\begin{array}{l}\text { Results } \\
\text { on Initial } \\
\text { Admission } \\
\left(1^{\text {st }} \mathbf{L P}\right)\end{array}$ \\
\hline $\mathrm{RBC}$ & $<1 / \mathrm{uL}$ & None & 2,356 \\
\hline WBC & $0-5 / \mathrm{uL}$ & 4 & 9 \\
\hline Character & Colorless & $\begin{array}{l}\text { Clear and } \\
\text { colorless }\end{array}$ & $\begin{array}{l}\text { Bloody, } \\
\text { Hazy }\end{array}$ \\
\hline Xanthochromia & None & None & None \\
\hline Glucose & $50-75 \mathrm{mg} / \mathrm{dL}$ & 47 & 56 \\
\hline Protein & $14-45 \mathrm{mg} / \mathrm{dL}$ & 69 & 78 \\
\hline Cryptococcus Ag & Negative & Negative & Negative \\
\hline Albumin & $0-35 \mathrm{mg} / \mathrm{dL}$ & 48 & - \\
\hline Alpha 1 & $0.0-3.1 \mathrm{mg} / \mathrm{dL}$ & 1.9 & - \\
\hline Alpha 2 & $0.0-5.4 \mathrm{mg} / \mathrm{dL}$ & 4.1 & - \\
\hline Beta & $0.0-8.1 \mathrm{mg} / \mathrm{dL}$ & 7.5 & - \\
\hline $\begin{array}{l}\text { IgG/Albumin } \\
\text { Ratio }\end{array}$ & $0.09-0.25$ & 0.02 & - \\
\hline Cytology & N/A & $\begin{array}{l}\text { Rare lymphocytes } \\
\text { seen }\end{array}$ & $\begin{array}{l}\text { Negative for } \\
\text { malignant } \\
\text { cells }\end{array}$ \\
\hline Bacterial culture & No growth & No growth & No growth \\
\hline Viral panel & Negative & Negative & Negative \\
\hline JC Virus by PCR & Not detected & Detected & $\begin{array}{l}\text { Not } \\
\text { detected }\end{array}$ \\
\hline
\end{tabular}

Table 2: Consensus Statement from the AAN Neuroinfectious disease on PML diagnostic criteria; summary of pathologic, clinical, and radiographic features of PML.

\begin{tabular}{|l|l|}
\hline \multirow{5}{*}{ Histopathology } & $\begin{array}{l}\text { Triad of (1) multifocal demyelination, (2) } \\
\text { hyperchromatic, enlarged oligodendroglial nuclei, } \\
\text { (3) enlarged bizarre astrocytes with lobulated } \\
\text { hyperchromatic nuclei with at least one of the } \\
\text { following: (a) Electron microscopic examination } \\
\text { or immunohistochemistry revealing JC virus, (b) } \\
\text { Tissue PCR for JC virus }\end{array}$ \\
\hline $\begin{array}{l}\text { Clinical Features/ } / \\
\text { Symptomatology } \\
\text { Most common symptoms include motor weakness, } \\
\text { gait abnormalities, visual field deficits, speech } \\
\text { and language disturbances, and incoordination. } \\
\text { Behavioral and cognitive abnormalities are seen } \\
\text { in one third to one half of patients. Less common } \\
\text { symptoms include sensory loss, seizures, headache, } \\
\text { and diplopia. }\end{array}$ \\
\hline Neuroimaging & $\begin{array}{l}\text { CT Scan will show hypodense lesions of the } \\
\text { affected white matter. MRI, which is the preferred } \\
\text { modality of imaging, will show hyperintense } \\
\text { lesions on T2-weighted images and fluid- } \\
\text { attenuated inversion recovery (FLAIR) images } \\
\text { of the cerebral gray-white junction or brainstem } \\
\text { white matter, +/- enhancement, +/- mild mass } \\
\text { effect. MR Spectroscopy will show decrease in } \\
\text { L-acetylaspartate and creatine and increased } \\
\text { choline products, myo-inositol, and lactate in the } \\
\text { lesions of PML. }\end{array}$ \\
\hline Studies & $\begin{array}{l}\text { On serum bloodwork, patients with PML have } \\
\text { been noted to have CD4 lymphocyte count <200 } \\
\text { cells/mm³. CSF studies have been shown to have } \\
\text { cell counts less than 20, and elevated protein levels } \\
\text { (mean value 66.5 mg/dL). CSF demonstrating the } \\
\text { presence of JC Virus by PCR. }\end{array}$ \\
\hline
\end{tabular}

\section{Discussion}

Historically, the diagnosis of PML has been dependent on brain histopathology via brain biopsy, an invasive procedure that poses considerable risk to the patient and is not without sampling error [3]. Brain biopsy remains the gold standard for diagnosis. However in 2013, the American Academy of Neurology (AAN) revised the diagnostic criteria of PML to include a combination of clinical, radiographic and laboratory data to establish a definitive diagnosis of PML when brain biopsy could not be obtained. In their statement, they described non-invasive diagnostic criteria including pathologic, clinical and radiograph features of PML along with positivity of JC virus DNA by PCR in the CSF (Table 2) [3]. In summary, the statement by AAN indicates that if either the quintessential clinical or radiographic features are not present, a "probable" diagnosis of PML can be made, in converse to a definitive diagnosis if all three categories are fulfilled. It should be emphasized that a diagnosis of "definite" versus "probable" PML does not change clinical management; patients with "probable" PML should still be managed as having PML, especially when considering its possibility in high-risk groups [3].

The diagnosis of PML using the criteria established by the AAN is reliant on the expression of the JC virus by PCR in CSF studies, in addition to either the classic symptomatology or radiographic findings. The JC virus PCR test is highly sensitive and highly specific; amplification of the virus from the CSF in the absence of PML is considered very unlikely [3]. According to the literature, investigations have been performed to examine the possibility of JC viral activation in patients diagnosed with other central nervous system (CNS) viral illnesses, such as herpes simplex virus type 1 (HSV-1) encephalitis, enteroviral and non-enteroviral meningitis, and multiple sclerosis (MS). Bogdanovic et al. studied CSF samples from 39 patients with HSV-1, 20 patients with enteroviral meningitis, and 15 patients with non-enteroviral meningitis in addition to $58 \mathrm{CSF}$ samples from 45 patients with multiple sclerosis to look for the presence of JC virus DNA using PCR. In all the collected samples of CSF, JC viral DNA was not detected thus confirming that detection of this virus in CSF is diagnostic for PML [4].

In our patient case, as brain biopsy was unfortunately unable to be obtained, the AAN diagnostic criteria was used to establish the diagnosis of PML. Our patient presented with hallmark signs of PML, including progressively worsening symptoms, motor weakness, gait disturbances, speech abnormalities and mood instability. She also had a pertinent history of recent Rituximab use, a medication with known association to PML. Our patient's radiographic findings showed suspicion for PML. On MRI brain imaging, hyperintensities on T2/FLAIR sequences were identified. These sequences increased in multitude and intensity throughout the duration of her hospitalization. As our patient 
had PML in the context of malignancy, her lesions were notably of temporal region, were not confluent and did not enhance. Conversely, typical PML findings on MRI imaging include confluent, bilateral but asymmetric supratentorial white matter disease most commonly in the frontal and parietal lobes, causing prominent hyperintensities to appear on FLAIR in the adjacent white matter and the cortex on T2-weighted sequences [5, 6]. However, while temporal and occipital lesions are a less common finding overall, it has been found that lesions in these areas are observed more in patients with malignancy and drug-associated PML [6]. Thirdly, and most importantly, JC virus DNA was detected via PCR in our patient's CSF. Thus, at the very least a "probable" diagnosis of PML was made.

Limbic encephalitis was included on the differential diagnosis of this patient, and notably was the leading diagnosis on her initial presentation given her more typical radiographic findings supporting this disease process. While EEG did show generalized slow wave activity, it remarkably lacked hyperintensities in the bilateral mesial temporal lobe structures and showed no evidence of electrographic seizures or definitive epileptiform activity. Unfortunately a neuro-oncologic antibody panel to further rule out limbic encephalitis was not obtained. However, as previously mentioned additional studies ultimately further supported the diagnosis of PML, specifically the isolation of JC virus via PCR of the CSF. While ideally more definitive evidence would have been acquired to confidently rule out limbic encephalitis, absence of highly specialized testing is an issue routinely faced by practitioners world-wide, whether it is due to lack of resources or late patient presentation/acquisition of patient care. Given the diagnostic work-up that was attained, criteria was met to establish at least a "probable" diagnosis of PML. Hence, this case presentation provides a valuable lesson as rarely in the literature has PML been established using diagnostic criteria in substitution to brain biopsy. The diagnosis of primary CNS lymphoma was also considered due to its propensity for immunosuppressed patients, similar to PML. Unfortunately, given the patient's untimely demise and the family's decision to decline autopsy, biopsy was not obtained. Interestingly, our literature review revealed a case report describing a concomitant diagnosis of PML and primary CNS lymphoma. In this case, post-mortem examination revealed characteristic features of both PML with cells expressing the JC virus as well as atypical plasmacytoid lymphocytes consistent with a neoplasm of B cell origin which also expressed the JC virus [7]. This calls for future studies to evaluate a potential link between JC virus and primary CNS lymphoma.

Our case highlights the development of PML following the use of Rituximab. Similar to our patient, Freim et al. described a case of a 44-year-old female treated with a chemotherapy regimen including Rituximab for the treatment of low-grade follicular B-cell lymphoma. Her presenting complaint of dysarthria was however initially attributed to a psychiatric medication side-effect. While adverse medication effects should be included in the differential, our patient case along with others in the literature highlight that clinicians should be cognizant of immunocompromised patients who develop new neurologic symptoms in the setting of recent Rituximab use. This is supported by a retrospective study by Carson et al. on PML diagnosed after Rituximab treatment in HIV-negative patients which revealed that the median time from the last Rituximab dose to diagnosis was 5.5 months, while the median time to death was 2 months [8]. This study also showed a significant increased mortality rate of $90 \%$ in this subset of patients, emphasizing the gravity of this disease and the importance of its recognition early-on.

Rituximab is an IgG anti-CD20 monoclonal antibody that has been approved in the United States for both the treatment of NHL as well for the treatment of severe rheumatoid arthritis in combination with methotrexate [9]. While it has been shown to increase disease-free survival and overall survival rates for many lymphoid malignancies, there has been an emerging association of Rituximab with PML, thus prompting a response from the US Food and Drug Administration (FDA). In 2007, the Rituximab label was changed to include a black box warning for PML [9]. Additionally, a plan was implemented by the FDA to enhance pharmacovigilance and clinician recognition which included ongoing post marketing surveillance, assessments of reporting rate, incidence, risk factors and morbidity and mortality of PML [9]. Despite efforts to bring awareness to the association between Rituximab and PML, and to highlight PML as a disease entity in general, this disease has been frequently overlooked. A retrospective study by Miskin et al. which looked at the diagnostic delay between PML symptom onset and the confirmation of diagnosis showed that almost $50 \%$ of the patients studied were diagnosed over 3 months after their initial symptoms began [10]. Patients with a limited diagnostic delay of less than 1 month had significantly better outcomes than those with a delayed diagnosis within 1-3 months [10]. Unfortunately, there are no proven treatments for PML due to rarity of the disease and thus lack of data [11]. We therefore aim to highlight the importance of recognizing the association of PML development in the immunosuppressed population after treatment with Rituximab to facilitate prompt treatment and care to improve patient outcomes.

\section{Conclusion}

We present this patient case to emphasize the importance of including PML early in the differential diagnosis upon the evaluation of immunosuppressed patients presenting with progressive neurologic symptoms such as motor weakness, gait and speech abnormalities, and mood instability after treatment with Rituximab. Additionally, we aim to increase education and awareness among clinicians in diagnosing PML without histopathological evidence via brain biopsy by using the AAN criteria including clinical manifestation, radiographic findings and laboratory data. PML is an extremely rare, life-threatening condition with a high mortality rate. Its relationship post Rituximab administration is emerging in the literature, and thus PML should be considered in the differential for patients who develop new neurologic symptoms. As the use of immunosuppressive agents and monoclonal antibodies such as Rituximab expand, the incidence of PML may also increase. 
Faster recognition and diagnosis of this disease are essential to better patient outcomes.

\section{References}

1. Progressive multifocal leukoencephalopathy. [https://www. ninds.nih.gov/Disorders/All-Disorders/Progressive-MultifocalLeukoencephalopathy-Information-Page\#disorders-r1] Accessed on: January 14, 2021.

2. Kartau M, Sipilä JO, Auvinen E, Palomäki M, Verkkoniemi-Ahola A 2019. Progressive multifocal leukoencephalopathy: current insights. Degener Neurol Neuromuscul Dis 2019(9): 109-121. https://doi. org/10.2147/DNND.S203405

3. Berger JR, Aksamit AJ, Clifford DB, Davis L, Koralnik IJ, et al. 2013. PML diagnostic criteria: consensus statement from the AAN Neuroinfectious Disease Section. Neurology 80(15): 1430-1438. https:// doi.org/10.1212/WNL.0b013e31828c2fa1

4. Bogdanovic G, Priftakis P, Hammarin AL, Söderström M, Samuelson A, et al. 1998. Detection of JC virus in cerebrospinal fluid (CSF) samples from patients with progressive multifocal leukoencephalopathy but not in CSF samples from patients with herpes simplex encephalitis, enteroviral meningitis, or multiple sclerosis. J Clin Microbiol 36(4): 1137-1138. https://doi.org/10.1128/JCM.36.4.1137-1138.1998

5. Bag AK, Curé JK, Chapman PR, Roberson GH, Shah R. 2010. JC virus infection of the brain. AJNR Am J Neuroradiol. 31(9): 1564-1576. https://doi.org/10.3174/ajnr.A2035

6. Maas RPPWM, Muller-Hansma AHG, Esselink RAJ, Murk JL, Warnke C, et al. 2016. Drug-associated progressive multifocal leukoencephalopathy: a clinical, radiological, and cerebrospinal fluid analysis of 326 cases. J Neurol 263(10): 2004-2021. https://doi. org/10.1007/s00415-016-8217-x

7. Gallia GL, DelValle L, Laine C,Curtis M, Khalili K. 2001. Concomitant progressive multifocal leucoencephalopathy and primary central nervous system lymphoma expressing JC virus oncogenic protein, large T antigen. Mol Pathol 54(5): 354-359. https://doi.org/10.1136/ mp.54.5.354

8. Carson KR, Evens AM, Richey EA, Habermann TM, Focosi D, et al. 2009. Progressive multifocal leukoencephalopathy after rituximab therapy in HIV-negative patients: a report of 57 cases from the Research on Adverse Drug Events and Reports project. Blood 113(20): 4834-4840. https://doi.org/10.1182/blood-2008-10-186999

9. Carson KR, Focosi D, Major EO, Petrini M, Richey EA, et al. 2009. Monoclonal antibody-associated progressive multifocal leucoencephalopathy in patients treated with rituximab, natalizumab, and efalizumab: a review from the research on adverse drug events and reports (RADAR) project. Lancet Oncol 10(8): 816-824. https://doi. org/10.1016/S1470-2045(09)70161-5

10. Miskin DP, Ngo LH, Koralnik IJ. 2016. Diagnostic delay in progressive multifocal leukoencephalopathy. Ann Clin Transl Neurol 3(5): 386-391. https://doi.org/10.1002/acn3.301

11. Bohra C, Sokol L, Dalia S. 2017. Progressive multifocal leukoencephalopathy and monoclonal antibodies: a review. Cancer Control 24(4): 1073274817729901. https://doi. org/10.1177/1073274817729901 